\title{
Otopalatodigital syndrome spectrum disorder
}

INSERM

\section{Source}

INSERM. (1999). Orphanet: an online rare disease and orphan drug data base. Otopalatodigital syndrome spectrum disorder. ORPHA:364541

Otopalatodigital syndrome spectrum disorder is a primary bone dysplasia and encompasses a group of cong enital anomalies that are characterized by skeletal dysplasia of varying clinical severity and an X linked dominant pattern of inheritance. This group includes otopalatodigital syndrome type 1 and 2 (OPD1, OPD2) which are characterized in affected males by cleft palate, conductive hearing loss, craniofacial abnormalities and skeletal dysplasia; Melnick-Needles syndrome (MNS) which displays skeletal deformities in females and embryonic or perinatal lethality in most males; frontometaphyseal dysplasia (FMD); and terminal osseous dysplasia - pigmentary defects. 